\title{
XV. On the means most proper to be resorted to for extinguishing accidental fires in ships. Read before the Askesian Society in December 1801
}

\section{Alexander Tilloch}

To cite this article: Alexander Tilloch (1805) XV. On the means most proper to be resorted to for extinguishing accidental fires in ships. Read before the Askesian Society in December 1801, Philosophical Magazine Series 1, 21:82, 97-110, DOI: 10.1080/14786440508676681

To link to this article: http://dx.doi.org/10.1080/14786440508676681

曲 Published online: 18 May 2009.

Submit your article to this journal $\pi$

山 Article views: 3

View related articles 


\section{$[97]$}

XV. On the Means most proper to be resorted to for extinguishing accidental Fires in Ships. By ALEXander Tillocir. Read before the Askesian Society in December 1801.

$\mathrm{I}_{\mathrm{T}}$ is impossible for human imagination to conceive any calamity more horrid and distressing than that of a ship on fire,-a species of accident to which vessels are much exposed, owing to the combustible nature of the materials of which they are constructed, and which, unhappily, too often baffles every effort to subdue it.

To discover some means by which those on board, in such circunstances, may extinguish the flames efficaciously and speedily, has long been a desideratum; for experience has but too fully proved, that buckets and fire-engines, with water, the methods heretofore resorted to, are not effectual. To point out such means as are calculated to arrest the progress of the devouring flames will not be thought an useless labour; nor will they be the less valued for being simple, and, in almost every case likely to occur, perfectly within the reach of the people. That the efficacy of the means to be proposed may be established on incontrovertible principles, it may be of some use to examine, previously, what takes place in deflagrations of the kind to which we allude. This inquiry will also probably lead us, to a knowledge of the cause why the methods usually employed prove inadequate to the end proposed.

The laws and operations of nature are extremely simple, and, if we attend to what she points out, we cannot be misled.

For maintaining the common process of combustion, certain conditions are indispensable.

1. A substance or substances capable of undergoing a chemical decomposition, and of entering, wholly or partially, into new combinations when circumstances favour the process.

Such are wood, tar, hemp, \&c.

2. The presence of some other substance which, by its decomposition, may furnish a principle or-principles capable of entering into union with those of the combustible substances, therelsy liberating caloric or the matter of heat, which, with the light also liberated, constitutes the most striking phænomena in combustion.

Atmospheric air is such a substance.

It is a fact well known, that the atmosphere consists of Vol. 21. No. 62. March 1905. G two 
two distinct substances dissolved in caloric or heat, which forms a third ingredient. The two first are oxygen and aizote.

The azote is in such strong chemical union with the caloric, in which it is dissolved, that, in no common process of combustion is the union destroyed: or, in other words, that portion of the heat of the atmosphere which is united to the azote is never liberated to exercise it action in form ing new combinations *.

It is otherwise, however, with the portion of heat united to the oxygenous part of the atmosphere. These two have so weak an affinity for each other, that a little increase of temperatuire is all that is necessary to determine their separation, if substances to which the oxygen can unite itself be present. In proportion as the oxygen joins itself to these substances, the heat thus liberated raises the temperature of other portions of them to that point which determines their union with oxygen ; thus more air becomes speedily decomposed, and all the phenomena of combustion are rendered more and more conspicuous, till complete deflagration precludes all possibility of clrecking the progress.

What office does water perform when employed for the purpose of checking the progress of a fire? It extinguishes the flame ly cutting off the communication between the burning body and the air which mainlains the combustion. But this it can do only in certain cases.

Waier is known to consist of two substances, oxygen and hydrogen. The former, as has already been noticed, is an ingredient also in atmospheric air, and is that substance which unites itself to the burning body in every case of combustion: the latter is the base of hydrogen gas or infammalle air.

Water, like atmospheric air, may be decomposed by presenting to it, under certain circumstances, substances for which either of its constituent principles has a stronger affinity than the two bave for each other.

When a fire has got to such a height that water cannot be thrown on it in suflicient quantity to:interpose itself as a wall of separation between the burning materials and the almosphere, but is itgelf instantly converted into vapour and decomposed, - in that case, instead of extinguishing, it adds

* It must be here observeh, however, that this remark should be taken with some limitation: modern chemistry is in some measure furced to suppose that the azote gocs to the formation "of alkalis when they result from the combustion; in which case the caloric may be supposed to exercise some action; but that affects not our general argument. 
to the defagration. Its oxygen joins the combustible materials, while its hydrogen, disengaged in the form of inflammable air, mixes with the atmospheric air present, and inflames almost as quickly as it is liberated.

A ship in such a case becomes filled with flames, even in those places where, before, there was no fire; and it may truly be said, these parts are set on fire BY WATER!

But water has been the only means hitherto employed to extinguish fires; and if this is not to be used, what other method can we resort to?

The question is answered in part by what we have stated respecting water when it succeeds in any case in extinguishing fire. Cut off ail communication between the burning body or bodies and the atmosphere.

The presence of air, we have already observed, is indispensably requisite to maintain combustion.

This fact has been long known, and it appears wonderful that advantage was never taken of it to extinguish fire in ships; especially when it is considered that their structure is such that, had this been one of the principal objects in view in the building of them, they could not possibly have been better constructed to enable us to take advantage of this law of nature.

If a glass jar be inverted over a burning taper in such a manner as to bring the mouth of the jar into contact with the table on which the taper stands, the flame soon grows languid, and in a little time we see it expire altogether. The oxygenous part of the atmosphere has been decomposed, and having, by that decomposition, given up all its oxygen to the combustible body, the process ceases of itself, not for want of fuel, but for want of a fresh portion of oxy-s genous air to be decomposed. If this experiment be performed over water, its ascent in the jar, as every one knows, will prove that a portion of the air has disappeared; its oxygen having become concrete in the burning body, or assumed a less volume in the new products formed, viz. carbonic acid gas and water; and that portion of its caloric not necessary to the formation of the acid gas having been liberated.

The larger the flame of the taper compared with the quantity of air; or, in other words, the smaller the quantity of air compared with the size of the burning body, the sooner does the process of combustion cease. It is on this principle that a common extinguisher puts out a candle.

These simple facts furnish us with sufficient data on which to found a rational and infallible method for extinguishing 
fite on board a ship. If the fire cannot be got at, and instantly extinguished with a bucket or two of water, no time should be wasted in fruitless attempts to reach the spot; for during all this time the prime auxiliary, the most formidable ingredient in the conflagration, viz. the atmospheric air, is allowed to pour itself upon the burning materials and to furnish the very essence of the flame,-for the fire Is FUHNISHED BY THE AIn, and not by the uood, tar, QSc ; a fact too well established to be insisted on here. Instead of suffering this to take place, all hands should be called up; the ports, hatches, Exc. should be shut, and every one.set to work to stop np with oakum, tallow, pitch, (any thing, every chink and crevice all over the vessel. She vould thus literally become a large extinguisher; and is would be just as rational to insist that a man could live deprued of fresh air, as to assert that fire can continue to burn in the interior of a ship when every possibility of a tresh supply of air is thus cut off.

Sxin is the general principle that ougbt to direet the proceedings of the officers and crew on every emergency of this kind. They ought all to be drilled to the business, that every one way know the particular station and specifie duty alloticd to him in case of such an accident taking place. This would be an antidote against that confusion and insubordination which almost always take place in cases of fre. The means are on infallibly certain in their effcet, that not only the offices, bnt a great number of the non would have tull confidence in the isste of their exentious; this would insure firmess, and the unruly would be as effectually kept in order as on any common occasion.

Fhe general principle we hive stated to be, the cutting off. elery possibility of a fresh supply of atmospheric air getting into the interior of the ship. But a still further advautage nay be taken of the natral laws before examined, s) as to hatien the destruction of the uhole air containd in the ship, and to render it unfit for maintaining comlustion. We have already brought to recollection, that the larer the mass of burning materials compared with the quantity of air present, the souner will the fire extinguish itsclf: this in a truth that cannot be too forcibly impressed on the minds both of the officers and crews; for, however fereely the fire may be raging below, the sooner with it be exting isishet if thcy can only succed in making extry thing air-tight above decks and round the ship (as the ports, scuttles, scuppers, windows, \&c.): the full conviction of this truth will prevent them from relaxing in their exertions, and wonder 
fully conduce to their ultimate safety. This is no small advantage that results from the law of nature now under considertion; but a further ase ought still to be made of it. If a mumber of fires lie made letacen decks, by setting fire to pitch and other inflammable substances in pots, stewpans, \&c., befóre closing down the hatches and making every thing air-tight, the sooner will the air left in the vesset be deprived of its uxygen, and the combustion of course be terminated.

Thas we see that FIRES MAY Be FMployed TO EXTINGUYSH FIRE; and the more there are of them, the sooner will all of them, as well as the prime fire, be extinguished. This is the more necessary because, if all the air in the interior of the vessel must expend itself in the prime fire, a hole may possibly be the consequence, and there fresh air. would rush in to maintain the flame; but a number of fires in different parts of the ressel would quickly destroy all the air, and render that accident impossible. In short, if the people be once made thornughly masters of their duty in such cases, they need not fear even to kindle fires on the bare loards for the purpose of extinguishing one where they cannot reach it ; for the cxalusion of fresh aip will soon arrest the progress of the flames.

If fears (groundless fears) should be entertained that such fires would increase the danger, candles may be employed with considerable effect. A good sized candle consumes about a gallon of air in one minute of time: several hundreds of them lighted between decks, before closing all up, would contribute not a little to exhaust the oxygen of the atmosphere. In short, proper receptacles for fires, to be employed for this express purpose, should constitute a part of the outfit of every ship, especially those of the royal navy and East India company. If such arrangements were made a part of the system (they surefy ough to be so), any fire below decks might le extinguishied in less than haly an hour.

It need hardly be remarked here, that in this case, as in every ease of danger, the foe should be opposed with firmness from post to post. If the fire breaks out in the hold, the first stand should be made on the lower deck. It onght instantly, and with deliberation, to be cleared, fore and aft, that not a chink or crevice may escape observation. Every opening, the pumps among others, ought to be closed, and the officers and men to be at their stations. This search. ought to be a close one; for the escape of smoke ought not to be lield as the only criterion of a seam being open. Where air is rushing in, smoke cannot come out; for two streams G 3 sunnot, 
cannot, at one and the same time, blow in opposite direct tions through the same aperture: therefore every seam should be examined; nor will it be difficult to do so, when it is considered in what a close and substantial manner ships are built.

While this is going on in the deck immediately above the fire, the officers and men on the next deck above should be preparing every thing for a second barrier to the ingress of air ; and so of the third deck : and each, before quitting their own deck, should light the extinguishing fres before recommended. Similar fires should, if possible, be introduced under the lower deck, the sooner to exhaust the air in the hold.

If these means be cooly and deliberately pursued, when a ship is on fire below or between decks the fiames may be as effectually extinguished as a burning candle when an extinguisher is put over it; the ship, as we have already said, is in fact converted into an extinguisher; nor is she less so on account of the combustible nature of the materials of which she is constructed: for a cone MADE OF PAPER extinguishes a candle as effectually as one made of metal. A lact of which any one may easily satisfy himself by making the experiment.

To discover when the conflagration is subdued, the test of a candle should be employed. For this purpose there ought to be a few places in each deck that can be opened when-necessary. Into one of these introduce a lantern and candle, taking care instantly to close the hole again. If the candle, after remaining a few minutes below, is found, on being drawn up, to have been extinguished, it may be concluded that all is safe, and that the air left is unfit for maintaining combustion. The people will then feel cheerful ; nor will they be impatient to open the decks when informed that, though the fire'is out, some articles may have attained such a high temperature, that the access of fresh air might occasion a new deflagration. Even when, by the test of a candle, it is found that all the air is destroyed, the precautions should be continued for a number of hours.

(It will occur from what has been stated, that if there be any particular part of a ship where fires are supposed to originate oftener than in any other, that part ought to be insulated, as it were, in the building of the vessel; that is, every part of it, all round, ought to be caulked up so as to make that room or apartment air-tight, that, when an accident occurs, no more might be necessary than to close the dour or entrance, and caulk it up.) 
In the preceding remarks we have pointed out the principles that ought to be kept constantly in view in every attempt to extinguish fire on board a ship. That we might not interrupt the connection we purposely avoided mentioning another mean which it might be advisable to provide against such accidents, and which depends on the same principles. The methods already laid down, if followed up with firmness, cannot fail to answer the purpose intended; but what we are going to mention would prove a most powerful auxiliary.

We have already noticed that the presence of oxygen in combination with caloric is an indispensable requisite in the process of combustion, and that atmospheric air contains these two ingredients in such a state of combination, and therefore serves to maintain combustion by giving up its oxygen to the combustible body, in conscquence of which its caloric is liberated. It follows from this, that the substitution of any gas for atmospheric air, or the intsoduction of any gas into the interior of the ship, to displace the whole or a part of the atmospheric air contained in it, would hasten the extinction of the flames, provided the gas so substituted for air be one that cannot be decomposed by the action of the fire.

It ought to be a gas that can be easily procured, and also one specifically heavier than atmospheric air, that it may descend, get below the common air, take its place in the vessel, and thus be certain (when a sufficient quantity is introduced) to reach the place on fire, and interpose itself as a wall of separation between the burning materials and the atmosphere.

Carbonic acid gas, or fixed air, is well calculated for this purpose. It can be procured even on board a ship with little trouble (if the proper requisites have been provided), and at a small expense. - It is considerably heavier thai common air, and extinguishes flame in a moment.

All that is necessary to insure a supply of any quantity in a very few minutes is, that each ship should be furnished with a certain stock of common oil of vitriol, (vinegar or any other acid would answer, but would be more expensive, ) and a quantity of common chalk or urburnt lime.

The sulphuric acid or oil of vitriol is an article of a much less dangerous nature, with respect to accidents, than is vulgarly believed. Compared with gunpowder, which.meants are found to kecp safe, even in a ship, it may be considered as perfectly harmless. Indeed, it ought to be put on board in a diluted state; and, in that case, would produce no 
more mischief, should a vessel of it by accident be broken or spilt, than as much strong vinegar. No good objection can therefore be offered against its use on the score of its being dangerous.

The chalk should be in powder, either in a dry state or diffused in water, and the vessels containing it should be so disposed and arranged in regard to those containing the diluted oil of vitriol, that, without needing to hunt for and arrange them in the hour of danger, (when the hurry and alarm might make it impossible to get at them, or to make a proper use of them when found,) no more might be necessary than to turn a cock, somewhere near the cabin, under the immediate eye of the commander or some intelligent officer, to allow the acid to convey itself through leaden pipes into the vessels containing the chalk or limestone.

The moment the sulpluric acid comes in contact with the chalk, the latter will be decomposed and part with the carbonic acid, one of its constituent principles, which will escape in the gaseous form, while the lime, its other principle, will remain united to the sulphuric acid.

All the articles connected with this process should be made of lead, or lined with it, as the sulphuric acid cxercises little or no action on that metal, which renders it preferable to every other material for the purpose.

The ways in which the parts of such an apparatus might the arranged to advantage are so various, that to insist on any one in particular is unnecessary. The principle of the arrangement is all that need be noticed here. The vessel or vessels containing the acid nust be in a higher situation than those containing the chalk or unburnt lime. The latter may be in the hold, or in any situation lower than the former; and pipes of communication, that can be opened or shut at pleasure by turning a cock, as alrady mentioned, must pass. from the vessels containing the acid to those in which the chalk is.

The latter, if in the hold, should have perforated covers, that the fixed air, when liberated from the limestone or chalk by the action of the sulphuric acid, mav have a free escape. If above any of the decks, a hose or tube should pass from their tops down to the hold and lower decks for the liberated gas to descend through. These tubes should be secured from injury by covering them with planks, or casing them at the time of their fitting up.

Such an apparatus as is here recommended would be found much more simple than it can possibly appear to be from a description, 
description, nor can any fire-engine that has ever yet been constructed be compared with it in point of simplicity. Still less will fire-engines bear comparison in point of eff̈cacy; for the gas that may be liberated by this simple apparatus will infallibly extinguish flames, but the water thrown by a fire-engine seldom succeeds in doing so, and often, as we have before proved on physical principles, increases their fury *

IVith a view to the application of the means for extinguishing fires which we have pointed out, care ought to be taken in fiture in the construction of ships, to fill up, at the decks, all the seams and joinings between the side timbers, that an air-tight line of division may reach from the decks even to the outside planks, to prevent all passage of air behind the linings: But I shall not inșist longer on this. The principles I have laid down are sufficiently obvious, and the only wonder is, that they have not been resorted to before this time as a safeguard against fires below and between decks.

As the minor details are perfectly obvious, and cannot fail to present themselves to the minds of those in whose department it may lie to give efficacy to the plan we have proposed, it would be carrying the present paper to an unnecessary length to enter into them. There is one point, however, that must not be ovellooked, being connected with the safety of the people:-

After the fire has been extinguished by the means that have been recommended, the air which remains in the interior of the vessel will be found as unfit for maintaining animal life as for maintaining combustion. It ivould instantly suffocate those who should descend into it ; and consists of two non-respirable gases, azotic gas and fixed air. It would be unsafe, therefore, to venture down till after the vessel has been ventilated by opening the ports from the outside of the ship, and by means of bellow's and leathern hose thrown down into the hold. In short, any or all the ways now emploved for ventilating ships may be employed to re move the foul air, and make it safe for the people to go down,

* It is possible that in some cases a vessel may not be able to afford rom for a sufficiency of these materials to furnish a quantity of fixed air eyual in volume to her hold, and there may be other objections to taking so large a supply which have not occurred to mey but as in a case of tire it mav be necessary to stave the rum and brandy on board, as mich ol of vitriol and chalk should always be provided as would furnish a stratum of fixed air able to rise a few inches at least over any spirits that may thus be staved into the hold. 
To determine when the air is sufficiently renewed to admit of this, a lantern with a burning candle should previously be let down at the end of a string. If, after being allowed to remain below for some time, it come up unextinguished, the people may venture down,-and so from deck to deck till they have got every part completely ventilated.

In the preceding observations I have confined myself to fires which may happen below or between decks; but as accidents (though this is perhaps less to be apprehended) may also take place above decks, or below the quarter-deck, \&c., where the same means cannot be employed for extinguishing them as in the former case, it may not be thought superfluous to offer a few hints for subduing them when they occur.

It is obvious that the means adapted to accidents below are inapplicable to such as may happen above decks; but it is equally nbvious, that, whatever method may be resorted to, it must agree in principle with the former. A wall of separation must be interposed between the burning materials and the atmosphere, or the flames cannot be extinguished.

Water, we have already seen, can but seldom be applied with effect for this purpose; and the experience of ages has only served to furnish evidence that it ought not to be trusted to: By its great volatility and its extreme liquidity (even if it could not be decomposed, and so add to the conflagration, as it has already been proved to do, ) it is but little fitted to remain on the places where its presence might be serviceable.

Some other matters, therefore, onght to be provided, that may, when employed, be able to serve as an effectual covering to the lurning materials, or to the suljacent parts of the vessel, to prevent the fire from penetrating dounwards. They ought to be such as can be met with in every port, and at the cheapest rate: such are sand, or mould, or clay.

The first is perhaps the best, because it can be moistened with water in a moment; though the last, if means could be insured for speedily converting it into a kind of soft pap or puddle, would answer better for throwing upon such burning parts as may be vertical or over head.

Every ship carries some ballast, or 'might carry as much as would be necessary for the end in view. A part of the ballast ought to be sand or clay, in bags or in small casks, and these ought to be so disposed in the hold, that, in the 
case of a fire above decks, they may be easily got at, and taken up. A number of buckets should also be provided that the people may not be without the means of hoisting. up the sand, \&c. even when the rigging takes fire and prevents them from employing a tackle for that purpose.

The sand, as brought up, should be thrown upon the burning materials, especially on those on the deck. Whereever it rests it will instantly extinguish the flames by preventing the access of atmospheric air. In fact, the whole deck, especially near the spot on fire, should be covered with sand to the depth of three inches, which will be much more easily accomplished than at first may appear possible; for the people have only to begin at the side of the fire next to them, covering the deck before them with sand, and spreading it with shovels, - thus making a road for them selves to advance upon, still covering more of the deck as they advance; an advantage that cannot be commanded by the use of mere water. By these means, even where the deck has been absolutely on fire, the flames will-be so effectually extinguished that the people may instantly walk over the place with perfect safety.

This will enable them to gain upon the fire, and with mops (especially if a clay puddle instead of water be employed) to dash out the flames on such parts of the sides (under the quarter-deck for instance) or over head as may have caught fire. Let it be particularly observed, that if means can be found to enable the people (sand, \&c., would enable them) to advance on the flames, in that case mops with water, or rather water mixed with clay or sand, applied directly to the burning wood, \&c., beginning at the part on fire immediately next to them, and proceeding step by step, will extinguish flame better than water throu'n from a fireengine. The reason is obvious: water so thrown on runs off by the most direct course it can find, and will not stop to spread itself over prominences or to penetrate into interstices; but when dashed on by means of mops, it has no choice, but must apply itself where it is intended it should.

I do not mean by this that a fire-engine ought in no case to be employed; but when resorted to, its jet should be directed forward further than, ihe people can yet advance, and never in such a manner as to wash away the bed of sand from the decks, or the coating of sand or clay that bas been applied by mops to the uprights and parts over head. And the moment the people can advance to apply mops, the engine should be stopt.

In mopping, the process should go on fiom the lower 
parts upwards; there will then be the least waste of labour; and consequently the greater chance of succass: for whet a contrary mode is followed (which is always more or less the case with water thrown on by an engine) the parts extinguished are again rekindled by the flames ascending from the lower parts, and which therefore ought first to be subdued.

Clay or sand is recommended to be applied with the water employed in mopping, that a kind of incrustation may be formed wherever the mops are applied; but in attending to this, the uniform continuity of the bed of sind, distributed and still distributing on the deck, must be carefully maintained; for this is the chief ultimate security that the men have for saving the hull of the vossel, and consequently their own lives.

The red-hot balls employed by the garrison of Gibraltar to destroy the Spanish floating batteries, were carried from the furnaces to the bastions in wooden barrows with only a layer of sand interposed; and this u'as found sufficient to prevent the balls, though in a high state of incandescence, from setting fire to the unogd. A fact so notorious renders it perfectly unnecessary to insist further on the efficacy of sand on the upper deck to prevent the descent of the fire frotm above.

As to the rigging, there appears but little hope of any means being ever devised to secure it effectually from the effects of a fire above dccks, and perhaps the least evil will result from clearing it away in such a case, and getting it overboard as fast as possible. I shall, however, venture to hint at one improvement. The hull is sheathed with copper as a guard against the worm.-Would there be any thing absurd in sheathing the masts with coppor to preserve them from fire? I think not: and the expense would be no object *. In that case an iron or copper chain (composed of very long links to make it require the less weight of metal) should accompany, each main-stay, to secure the masts in any case when the other rigging might be destroyed by fire. The chains, of course, would require to be less tight than the stays, that they might only act in case of the other being destroyed.

All the upper works ought to be covered with sheet copper to secure the side timbers from being set on fire by any

- This could be done without increasing tbe weight of the masts; for the copper would add so considerably to their strength, that they might be made murch smaller thau at present. 
accident that may happen above the -upper deck. This would effectually answor the end intended; for as to those parts where cross timbers of any kind join the side, and where consequently the fire might communicate, they could individually be extinguished in sticcession, by the means we have pointed out, with much less trouble than if all the upper.works were exposed to the accident.

But, though we recommend sheet copper as a covering for the upper works, which surely ought to be as well secured against fire as the lower are against the worm and against water, even if this improvement be not adopted, the means we have pointed out (wet sand, wet mould, and wet clay,) should be provided to enable the people to extinguish the parts in detail till they master the fire; which in many cases they will be able to accomplish when the application of water would not be of the smallest avail. I need hardly add, that when any part of the cargo consists of articles that will of themselves, by the aid of an increased temperature, furnish a sufficient supply of exygen to maintain combustion without the aid of atmospheric air, fas for instance saltpetre, such part of the cargo shonld be disposed low in the hold, and should, if possible, bo cut off fiom all communication with the other parts of the lading, that, should a fire happen, there may be the less chance of its being communicated to that part of the cargo. For this purpose a part of the hold should be set aside, and ought to be boarded up, caulked, and covered with sheet copper. If that cannot be done, a false flooring should be laid in above that part of the cargo, which should be covered over with coarse matting of any kind: over the matting there ought to be a layer of sand or earth of two or three inches in thickness, and over the sand another cover of matting, to prevent it from being displaced by the stowing of the rest of the cargo.

But whether such arrangements are practicable respecting the oxygenous parts of the cargo or not, the other general precautions ought to be strictly enjoined, and the people should be appointed and trained to their respective duties in case of fire: books of instrucuions should also be profusely distributed amoning the officers and crews', and these instructions ought to be drawn up in a manner so plain and simple that no one may be at a loss to' know what is necessary to be done, whether he inderstand the scientific principles on which they are foumded or not. But the better the crew in general, and the officers in particutat, nnder- 
stand the science of extinguishing. flres, the more effectual will their endeavours be in every case.

Though in this essay I have taken no notice of cases of spontaneous ignition, the principles recommended are equally applicable to these as to other cases of fire. Even when the exciting cause of the combustion may be in the cargo itself, it cannot be maintained without the access of atmospheric air.

XVI. Memoit on the Natural History of the Coco-nut Tree and the Areca-nut Tree; the Cultivation of them according to the Methods of the Hindoos; their Productions, and their Utility in the Arts and for the Purposes of domestic Economy. By M. LE GovX DE FuAtx, an Officer of Engineers, and Member of the Asiatic Society at Calcutta.

\section{[Concluded fiom p. 8o.]}

IHE areca-tree is that beautiful palm which Linneus has so judiciously characterized by giving it the name of catechu, because its ligneous nut furmishes cachou by means of an easy preparation. This fact, though contradicted by: a great number of authors, is no less certain; and I propose to prove it in the course of this paper.

This tree is called pakmarou in almost all the languages of the peninsula; in the Hindostanee, the modern idiom of that antient country, it is denominated soupari, which signilies the areca-tree.

Though this palm is not so extensively useful in all its parts as the coco-nut tree, it is no less necessary to the Hindoos and the inbabitants of that vast part of the world called the East Indies, who all employ themseives in the cultivation of it.

The areca-tree, without having the beauty and port of the coco-nut trce, is of an elegant and agreeable form. It always rises vertically, and nothing is able to derange its direction. It is attacked by no insects : they are all kept at a distance by the soirness of its juice, and of its gum. Its stem is somewhat thicker in the middle, but slender, smooth, and perfectly well proportioned in all its parts.

Its foliage presents an agreeable spectacle by the regular arraugement of its palms, which are known in botany by the name of spadix, to characterize their form, and in general that of the branches of this family. The palms in 